\title{
Peer Learning: An Effective Teaching-Learning Method for Improving Ability in Arterial Blood Gases Interpretation
}

\author{
Riana Mauliandari ${ }^{1}$, Made Sumarwati ${ }^{1}$, Arif Setyo Upoyo ${ }^{1}$ \\ ${ }^{1}$ Faculty of Health Sciences, Jenderal Soedirman University, Purwokerto, Indonesia \\ Corresponding Author: Riana Mauliandari (mauliandari@gmail.com)
}

Received: 27 February 2020

Revised: 16 December 2020

Accepted: 21 December 2020

\begin{abstract}
Background: Competent nurses are expected to be able to interpret arterial blood gases (ABGs). The benefits of peer learning, an innovative teaching-learning method today, have long been recognized. However, to date, no studies have compared the effect of this method and the traditional classical method in interpreting ABGs.

Purpose: This study aimed to compare the effect of peer learning and classical learning methods on the nurses' ability to interpret ABGs.

Method: This was a quasi-experimental research with pre and post-test design. Forty ward nurses were invited in the peer learning method group, and another 40 ward nurses were invited in the classical learning method group through a randomization process. Data were collected using a questionnaire before and after the educational intervention. The classical class was taught by an experienced trainer, while peer groups, divided into groups of 5-6, were taught by one member of each group who obtained the best pre-test score and received special training first. The analysis of data was performed by t-test.

Result: The result showed that after the intervention, the mean score of interpreting ABGs in the peer learning group increased by $3.18 \pm 1.12(p<0.001)$, while in the classical learning method, it only increased by $2.32 \pm 0.988(p<0.001)$. Although there were significant increases in ABGs analysis's ability in both groups, the peer teachinglearning group demonstrated a significantly greater improvement in interpreting $A B G s$ $(p=0.001)$.

Conclusion: The peer learning method facilitates a more significant improvement in the nurses' ability for ABGs interpretation. Peer learning is appropriate as one of the methods in clinical education for nurses.
\end{abstract}

Keywords: ABGs analysis; classical teaching-learning; peer teaching-learning

How to Cite: Mauliandari, R., Sumarwati, M., \& Upoyo, A. S. (2020). Peer learning: An effective teaching-learning method for improving ability in arterial blood gases interpretation. Nurse Media Journal of Nursing, 10(3), 329-338. doi:10.14710/nmjn.v10i3.28660

Permalink/DOI: https://doi.org/10.14710/nmjn.v10i3.28660

\section{BACKGROUND}

One common investigation for monitoring the patient's respiratory status is through arterial blood gases (ABGs) analysis. The ABGs analysis is also applied to assess the 
need for oxygen therapy in patients (Jeeva, 2019; Mohammed \& Abdelatief, 2015). The result of ABGs interpretation can help in the assessment of a patient's gas exchange, ventilatory control, and acid-base balance. It indicates blood $\mathrm{pH}$, carbon dioxide, or bicarbonate concentrations (Jeeva, 2019).

Nurses in clinical practice are usually involved in taking and analyzing ABGs. Nurses regularly report the $\mathrm{ABG}$ results to the physicians. Based on these results, the physician will determine the patient's specific respiratory problems and prescribe a therapy or further treatment. Nurses' reports on the results of ABGs may influence the establishing diagnosis and treatment (Mathew, Hemavati, Pillai \& Biswal, 2014). Therefore, nurses need to be able to analyze each component of the ABGs. Nurses must be familiar with the information obtained in the ABGs' results (Safwat \& Khorais, 2018). Failure to see a change that is shown on the ABGs' results could result in an inaccurate interpretation and may lead to inappropriate treatment (Barnette \& Kautz, 2013). In Indonesia, the level I of clinical nurses must be able to interpret ABGs.

ABG analysis is a complex concept requiring a great deal of study in order to improve the knowledge regarding $\mathrm{ABG}$ and interpretation of results. Research found that some nurses had deficit knowledge of ABGs' interpretation. In India, one study was conducted to assess the knowledge of 30 nurses in analyzing and interpreting ABGs, and it found that none of them had an excellent grade and that $20 \%$ of staff nurses had less than 55\% of this knowledge (Jeeva, 2019). In a large hospital in Yogyakarta, where this study took place, a preliminary assessment of 12 nurses found that $66.7 \%$ were unable to interpret ABGs accurately. These results indicate a need for efforts to increase nurses' knowledge so that they are able to interpret ABGs correctly.

In order to increase nurses' abilities in interpreting ABGs, the hospital needs to arrange classes regularly to deepen the understanding of ABGs and their interpretations. The common teaching-learning method that is usually applied in the hospital is a classical method. The classical teaching-learning method is a method where the teacher serves as a center of learning while students listen to the material delivered by the teacher $(\mathrm{Xu}$, 2016). The method may not be the most interactive and participative teaching method (Hassan, Aslam, Shah, \& Luqman, 2016; Radha \& Chandekar, 2013). The class is scheduled according to the agreement of time and place by teachers and students (Mathew et al., 2014). The hospital needs to continue improving nurses' ability, so it is essential to assess the effectiveness of this learning method or find another better method. Comparing classical methods with other learning methods can be a reasonable solution to find new and better methods.

One of the innovative teaching methods that are relevant today is the peer learning method. Peer learning applies to learning methods in small groups and is studentcentered, which provides educational benefits to the instructors (tutors) and participants (tutees) (Yu et al., 2011). Peer learning provides tutors and students an opportunity to learn and teach one another, where tutees feel more comfortable learning with friends, thereby increasing learning activity (Gray, Wheat, Christensen \& Craft, 2019). Furthermore, it is believed that this method can make the learners easily understand the content and can keep the learners motivated and engaged. This method transfers the learning responsibilities from the instructors to the students (Stone, Cooper \& Cant, 
2013). Since this method makes students more responsible for their learning, it is convinced to be the most excellent way to learn, including ABGs. Meehan and Beinlich (2014) have proven that peer-to-peer learning/teaching is an effective way to change practices and prevent pressure ulcers in surgical patients. Surabenjawong et al. (2020) proved that the peer-to-peer method of instruction is not inferior to the standard instructor-led method to increase students' level of knowledge and confidence.

There were relatively many learning methods about ABGs, but only a few were specific on ABGs interpretation. Mathew et al. (2014) revealed that the structured teaching program effectively improved ICU staff nurses' knowledge of ABG interpretation. Basnett, Devi, and Chetia (2016) found that pocket reference effectively improved nurses' knowledge regarding ABG interpretation. Peer learning, a method that excels in creating a relaxed atmosphere to support the learning process enormously (Gray et al. 2019; Yu et al., 2011), has never been tested to increase nurses' ability to interpret ABGs. There have been no reports in the literature on peer learning methods in interpreting $\mathrm{ABGs}$ results for nurses. $\mathrm{ABG}$ interpretation can be a daunting and challenging concept for students and new nurses to grasp; furthermore, Barnette \& Kautz (2013) did not mention that peer learning was one of the ways to teach arterial blood gas interpretation. Therefore, it became a challenge to test whether this method effectively increased nurses' ability to interpret ABGs.

\section{PURPOSE}

This study aimed to compare the effect of peer learning and classical learning methods on the nurses' ability to interpret ABGs.

\section{METHODS}

\section{Research design and samples}

This study used a quasi-experimental research design with pre and post-test comparisons of two group designs. This study was conducted in Yogyakarta's largest hospital in December 2019. Using a random sampling technique, level I and II clinical ward nurses with ages 25-45 years old who had never attended emergency training and never worked in critical care were invited. Based on these criteria, a total of 218 nurses were filtered into 134, a lottery was done to divide the peer group and the classical group. According to the earlier similar research (Brannagan et al., 2013), the calculation determines that a sample of 40 participants in each group was sufficient. The participants' flowchart in this study is presented in figure 1 .

\section{Measurements}

The data were collected using a questionnaire that consisted of two parts: demographic data and ABGs result analysis. The demographic questions consisted of the nurse's age, gender, duration of work experience, and nursing education background. The ABGs analysis part consisted of 20 items of multiple-choice examination related to ABGs components. The ABGs component questions were developed to focus on the most frequently used parameters and often adequate in diagnosing and managing most clinical situations - $\mathrm{PaO} 2, \mathrm{SaO} 2, \mathrm{pH}, \mathrm{PaCO} 2, \mathrm{HCO}_{3}$, and lactate. The questions had been tested for validity and reliability. The questions showed an overall item-level content validity index (I-CVI) of 1 . The item-level response process validity index of 1.00 was obtained from ten clinical nurses I and II, inferring that each item was clear 
and comprehensible. The logical validity of the instrument was conducted by four experts (one physician and three critical nurses) who independently evaluated the instrument. Expert judgment results were calculated using the Aiken's V formula with a $\mathrm{V}$ result of 0.970 . The reliability analysis to determine the internal consistency of the instrument was performed on 30 nurses. The Cronbach alpha value for the items was 0.826 that confirmed the reliability of the instrument $(p<0.05)$.

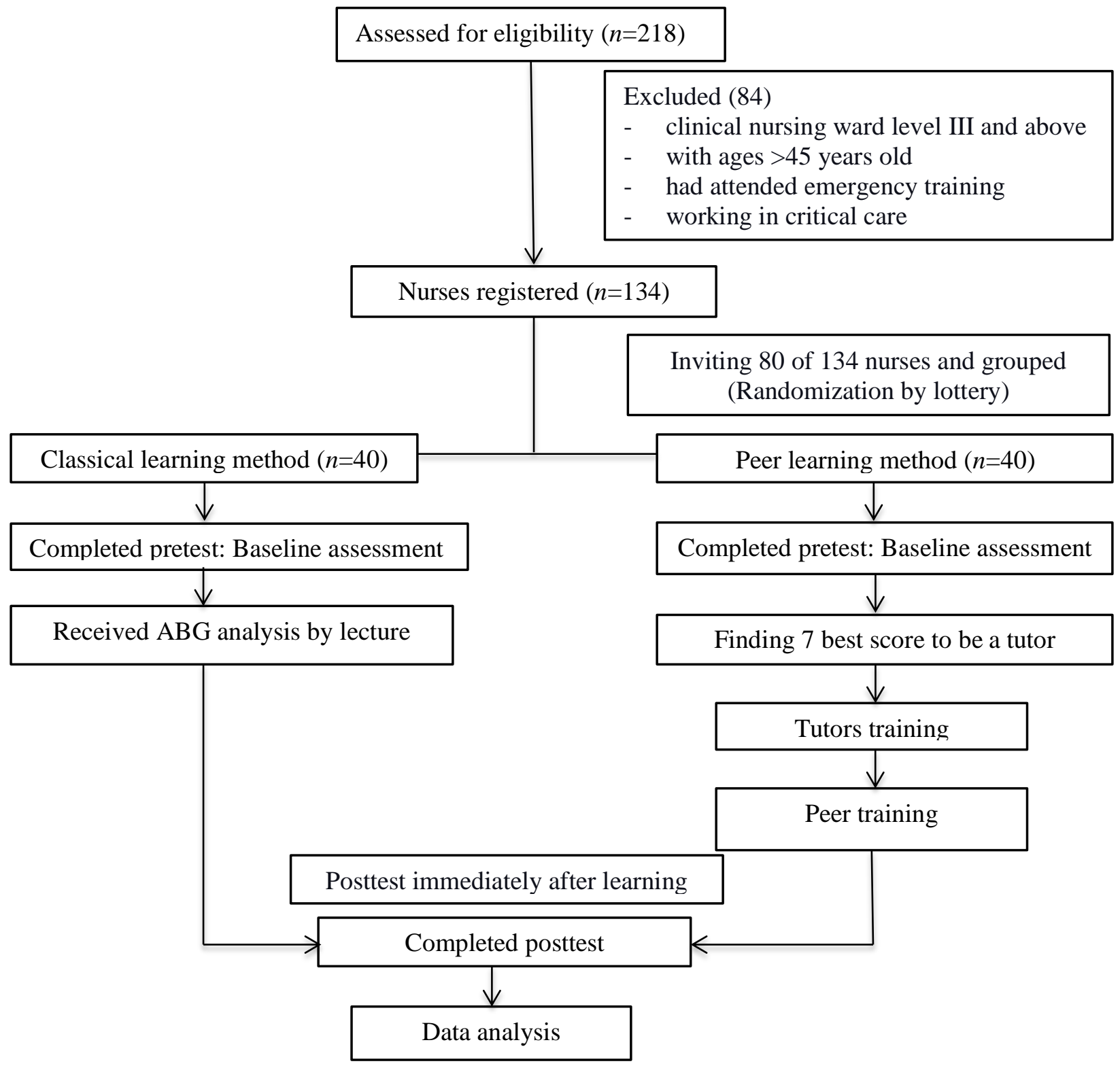

Figure 1. Flowchart of the study

\section{Intervention}

First, both groups underwent a pre-test. Next, the classical study group followed a learning session about ABGs and how to interpret the result. The material was given by a trainer who had received certificates to train ABGs. During the training, the participants were explained about the course objectives and guided through a lecture 
with PowerPoint slides. The participants had the opportunity to do questions and answers. The participants completed the post-test immediately after learning was concluded. On the other hand, in the peer learning group, seven participants with the best scores based on the pre-test results were placed as tutors and received special ABGs interpretation training given by the same trainer as the classical class to deepen the ABGs interpretation. After completing the training, these tutors shared knowledge in small groups with 4-5 participants in a different time. At the time set by each group, training with a peer was carried out and ended with a post-test.

\section{Data analysis}

The paired t-test with a $95 \%$ confidence interval (CI) was applied to measure the difference between the pre and post-test of the two groups, and the independent t-test was used to determine the effect of the methods.

\section{Ethical considerations}

This study was approved by the Research Ethics Committee of Faculty of Medicine, Public Health, and Nursing, University of Gadjah Mada (No. KE/FK/1377/EC/2019). The study purposes and details were explained to the respondents, and all respondents reviewed and signed the voluntary participation and informed the consent form before starting the study.

\section{RESULT}

\section{Characteristics of participants}

The characteristics of the participants in the two groups showed no differences (Table 1). The majority were females, graduated from Diploma nursing education, and the level I clinical nurse category.

Table 1. Characteristics of participants $(n=80)$

\begin{tabular}{|c|c|c|c|c|c|}
\hline \multirow[t]{2}{*}{ Characteristics } & \multicolumn{2}{|c|}{$\begin{array}{l}\text { Peer Learning Group } \\
\qquad(\mathrm{n}=40)\end{array}$} & \multicolumn{2}{|c|}{$\begin{array}{l}\text { Classical Learning } \\
\text { Group }(n=40)\end{array}$} & \multirow[t]{2}{*}{$p$} \\
\hline & $f$ & $\%$ & $f$ & $\%$ & \\
\hline Age (years old) & \multirow{2}{*}{\multicolumn{2}{|c|}{$32(26-43)$}} & \multirow{2}{*}{\multicolumn{2}{|c|}{$31(25-45)$}} & \\
\hline Median (min-max) & & & & & $0.582 *$ \\
\hline Working experience & \multirow{2}{*}{\multicolumn{2}{|c|}{$9(2-23)$}} & & & \\
\hline Median (min-max) & & & \multicolumn{2}{|c|}{$8(2-25)$} & $0.904 *$ \\
\hline \multicolumn{6}{|l|}{ Gender } \\
\hline Male & 11 & 27.5 & 9 & 22.5 & \multirow[t]{2}{*}{$0.399 * *$} \\
\hline Female & 29 & 72.5 & 31 & 77.5 & \\
\hline \multicolumn{6}{|l|}{ Education } \\
\hline Diploma & 27 & 67.5 & 29 & 72.5 & \multirow[t]{2}{*}{$1.00 * *$} \\
\hline Undergraduate & 13 & 32.5 & 11 & 27.5 & \\
\hline \multicolumn{6}{|l|}{ Clinical nurse category } \\
\hline Level I & 29 & 72.5 & 25 & 62.5 & \multirow[t]{2}{*}{$0.273 * *$} \\
\hline Level II & 11 & 27.5 & 15 & 37.5 & \\
\hline
\end{tabular}

*Mann-Whitney test, **Fisher's exact test 


\section{The effect of peer learning and classical learning methods}

The result showed that after the learning, the score of ability in interpreting ABGs result in peer learning increased from $5.51 \pm 1.35$ to $8.60 \pm 0.90$, while the score in the classical learning group increased from $6.04 \pm 1.25$ to $8.34 \pm 1.03$ (Table 2). The result showed that both groups experienced a significant increase in the ability to interpret ABGs' results $(p<0.001)$.

The independent t-test was run on the data, with a 95\% confidence interval (CI) for the mean difference. Table 2 indicated that the two groups were homogeneous in their preintervention scores $(p=0.082)$. Although there was no difference in the ability to interpret $\mathrm{ABGs}$ between the two groups after the training $(p=0.230)$, statistical tests showed that classes with the peer teaching-learning method provided a significantly greater range of improvement in interpreting ABGs $(p=0.001)$.

Table 2. The effect of peer learning and classical learning methods

\begin{tabular}{cccccc}
\hline Group & $\begin{array}{c}\text { Pre-test } \\
\text { Mean } \pm S D \\
(\mathrm{n}=40)\end{array}$ & $\begin{array}{c}\text { Post-test } \\
\text { Mean } \pm \text { SD } \\
(\mathrm{n}=40)\end{array}$ & $\begin{array}{c}\text { Mean } \\
\text { Difference } \pm S D\end{array}$ & $t$ & $p$ \\
\hline Peer learning & $5.51 \pm 1.35$ & $8.60 \pm 0.90$ & $3.18 \pm 1.12$ & -14.44 & $<0.001^{*}$ \\
Classical learning & $6.04 \pm 1.25$ & $8.34 \pm 1.03$ & $2.32 \pm 0.99$ & -18.34 & $<0.001^{*}$ \\
$\mathrm{t}$ & 0.51 & -0.26 & -3.35 & & \\
$p$ & $0.082^{* *}$ & $0.230^{* *}$ & $0.001^{* *}$ & & \\
\hline
\end{tabular}

*Paired-sample t-test, ${ }^{* *}$ Independent-sample t-test

\section{DISCUSSION}

This study aimed to compare the effect of peer learning and classical learning methods on the nurses' ability to interpret ABG analysis. This study demonstrated that both methods significantly improved the nurses' ability to interpret ABG results.

The finding showed that peer learning improves the nurse's ability to interpret ABG results. This finding is in line with the research conducted by Polkowskia, Jadejab and Duttac (2020) wherein the class with peer learning method was conducted, the student performance was higher compared to the performance of traditional methods. As group characteristics, peer learning can significantly improve participants' ability to interpret ABG results because learning in small groups increases member involvement in problem-solving and understanding the material (Tandel et al., 2019). In the group, the progress of one member in understanding material will inspire other members to achieve. Since they are peers and familiar with each other, each learner motivates to help one another, share knowledge, and eliminate the awkwardness to ask questions (Husain, Kusuma \& Johan, 2020; Meehan, 2014). Peer learning also allows learners to get a better understanding of the topic. Peer learning can reduce the respondent's anxiety as it increases the sense of comfort when learning, whereas the comfort of learning will affect one's learning outcomes (Gray et al., 2019).

The classical group participants have also experienced an increase in ability to interpret ABGs significantly. This study showed that although lecturing seems to be a somewhat old teaching method, it is still validly used to increase learners' understanding. This 
study's results correspond with previous research on the interpretation of ABGs, and it was found that after classical structured learning, there was a significant influence on the value of respondents' knowledge and skills (Kaur \& Charan, 2018).

In this study, the classical learning method could improve ABG nurses' interpretation ability because of several factors. One factor is the trainer. In this study, the trainer had received certificates to train and had often been taught how to interpret $A B G$ results in the hospital. A well-experienced trainer is positively associated with student achievement since the trainer can focus on learning and emphasize practical aspects to fit what learners need (Podolsky, Kini \& Darling-Hammond, 2019). Besides the experienced trainer, the factor that affects the improvement of ABG's ability is the profile of the participants themselves. The participants in this study were nurses who had a nursing diploma educational background and worked for an average of 8 years. Hailikari, Tuononen, and Parpala (2018) found that students who already had experienced had fewer obstacles in their studies. The process of teaching also influences the achievement of learning. At the beginning of the teaching, the learning objectives were delivered. Delivering the learning objectives encouraged participants to focus on the learning outcomes. The material was presented systematically, providing clear information that can improve learners' concentration to learn (Xu, 2016). Lastly, there was a question-answer session. This session is essential because it creates trainer-learner interaction and provides learners with opportunities to express understanding and ascertain learners' personal difficulties (Radha \& Chandekar, 2013).

Comparing the effect of peer learning and classical methods, the findings showed that there was no difference in groups' ability to interpret ABGs after learning. However, the peer learning group experienced more significant improvement than the classical learning group even though both methods increased nurses' ability to interpret ABGs. Similar to the research of Stone et al. (2013) which found that peer learning methods and classical conventional methods were equally able to improve the ability of nursing students to develop skills, communicate and think critically, this study showed that peer learning methods helped to increase nurses' ability to interpret ABGs than classical methods. Thus, this supports the study of El-Sayed, Metwally, and Abdeen (2013) and Dwijayanto, Wijayanti and Supardi (2018) that peer learning methods give a more significant effect on increasing knowledge than conventional classroom methods.

There are several factors which influence the difference in improvement between classical learning groups and peer learning. First, compared to classical methods, peer learning surpasses in providing a more relaxed and less intimidating environment (Gray et al., 2019). A relaxing environment made participants easier to communicate their doubts, lack of understanding, or misunderstanding. The participants were free to express their understanding without judgment or intimidation. Some learners were more intimidated by larger groups. Anxiety in peer learning was also low-level; therefore, peer learning can promote discussions and solve problems (Ribera, Gato, Guillem \& Pérez, 2014). In the classical learning method and peer learning, the participant may experience reflective knowledge-building by linking their past practical experiences with learning. Second, being in small groups and with peers, participants experienced reflective knowledge-building and each member gets a great opportunity to express themselves (Gray et al., 2019; Polkowskia et al., 2020). Unlike peer learning, 
reflective knowledge-building in classical learning depends on the trainer's ability to stimulate it; besides, each student keeps it in his or her own mind. Building reflective knowledge facilitated better understanding and deepened knowledge. Third, in the peer learning method with 5-6 nurses in each group, scheduling and venue arrangement were not difficult to carry out. It is different from the classical learning method where participants need to spend time and sacrifice other interests according to a particular schedule. Thus, this method can result in low motivation or a lack of compulsion and, ultimately, influence the results (Wijnia, Loyens \& Derous, 2011).

The test's maximum score in this study was 10, yet the achievement of both groups was less than $90 \%$ (the mean of the post-test was $8.60 \pm 0.90$ in peer learning and $8.34 \pm 1.03$ in the classical learning method). This may occur due to the participants' physical condition, in which the participants in both groups were off-duty nurses. The physical conditions and fatigue experienced by night-shift nurses may influence the participants' performance. Physical conditions and anxiety influence nurses' critical thinking skills (Ribera et al., 2014). The peer learning method and the classical method have their particular advantages. Both methods can be applied to increase nurses' ability in interpreting the result of $\mathrm{ABGs}$, but the statistical test presented a more significant improvement in the peer learning group than the classical group.

This study has a limitation. The pre and post-tests were both using the same questions and asked immediately after learning methods, which could result in test-retest bias, falsely inflating correct responses. Thus, it was highly recommended to do another posttest seven days after learning was completed.

\section{CONCLUSION}

The findings showed a marked increase in the score on interpreting ABGs before and after the intervention of the two groups. The peer teaching-learning method, however, showed a significantly higher improvement in the score, which indicates that this method is more effective in increasing the ability of nurses to interpret ABGs. The researchers recommend that hospital institutions improve staff competence by applying peer teaching-learning methods because this study demonstrates that the method gave more remarkable improvement for nurses. Furthermore, nurse colleagues are expected to keep and improve their competence in interpreting ABGs by regularly studying with peers (peer learning). It is expected for further researchers to conduct a study on ABGs interpretation by lengthening the post-test.

\section{ACKNOWLEDGEMENT}

The authors would like to thank all participants in this study.

\section{CONFLICT OF INTEREST}

The authors report no conflict of interest.

\section{REFERENCES}

Barnette, L., \& Kautz, D. D. (2013). Creative ways to teach arterial blood gas interpretation. Dimensions of Critical Care Nursing, 32(2), 84-87. doi:10.1097/DCC.0b013e31826bc732 
Basnett, S., Devi, M. B., \& Chetia, P. (2016). Effectiveness of pocket reference on arterial blood gas analysis among the staff nurses working in critical care units. Manipal Journal of Nursing and Health Sciences, 2(2), 25-28.

Brannagan, K.B., Dellinger, A., Thomas, J., Mitchell, D., Lewis-Trabeaux, S. \& Dupre, S. (2013). Impact of peer teaching on nursing students: Perceptions of learning environment, self-efficacy, and knowledge. Nurse Education Today, 33(11), 1440-1447. doi:10.1016/j.nedt.2012.11.018

Dwijayanto, I. M. R., Wijayanti, C. D., \& Supardi, S. (2018). The effect of peer learning to nursing care knowledge and occupational stress of the novice nurse. Indonesian Journal of Health Research, 1(2), 49-58. doi:10.32805/ijhr.2018.1.2.13

El-Sayed, S. H., Metwally, F. G., \& Abdeen, M. A. (2013). Effect of peer teaching on the performance of undergraduate nursing students enrolled in nursing administration course. Journal of Nursing Education and Practice, 3(9), 156-166. doi:10.5430/jnep.v3n9p156

Gray, S., Wheat, M., Christensen, M., \& Craft, J. (2019). Snaps+: Peer-to-peer and academic support in developing clinical skills excellence in undergraduate nursing students: an exploratory study. Nurse Education Today, 73, 712. doi:10.1016/j.nedt.2018.10.006

Hailikari, T., Tuononen, T., \& Parpala, A. (2018). Students' experiences of the factors affecting their study progress: differences in study profiles. Journal of Further and Higher Education, 42(1), 112. doi:10.1080/0309877X.2016.1188898

Hassan, S.H., Aslam, A., Shah, Z.H., \& Luqman, M. (2016). Lecturing effectively: Borrowing from the theories of teaching and learning: A review of literature. Pakistan Armed Forces Medical Journal, 66(3), 435-38.

Husain, F., Kusuma, H., \& Johan, A. (2020). Effects of peer support program on selfmanagement in patients with end-stage renal disease undergoing hemodialysis. Nurse Media Journal of Nursing, 10(2), 171-181. doi:10.14710/nmjn.v10i2.26502

Jeeva, S. (2019). A study to assess the knowledge regarding ABG analysis and interpretation of ABG results among staff nurses. Management of Cardiovascular and Orthopedic Complications, 2(1), 7-10. doi:10.5281/zenodo.3484609

Kaur, A., \& Charan, G. S. (2018). A study to assess the effectiveness of STP on knowledge and practice regarding ABGs among ICU nurses in selected hospitals at Jalandhar, Punjab. International Journal of Health Sciences \& Research 8(8), 182-188.

Mathew, R., Hemavati, G., Pillai, S., \& Biswal, A. (2014). A study to assess the effectiveness of structured teaching programme regarding arterial blood gas analysis and interpretation in terms of knowledge among nurses working in ICU in selected hospitals of Indore (MP). International Journal of Nursing Education and Research, 2(4), 286-289. doi:10.5958/2231-5713

Meehan, A. \& Beinlich, N. (2014). Peer-to-peer learning/teaching: An effective strategy for changing practice and preventing pressure ulcers in the surgical patient. International journal of Orthopaedic and trauma Nursing, 18(2), 12228. doi:10.1016/j.ijotn.2013.12.004

Mohammed, H. M., \& Abdelatief, D. A. (2015). Easy blood gas analysis: Implications for nursing. Egyptian Journal of Chest Diseases and Tuberculosis, 65(1), 369376. doi:10.1016/j.ejcdt.2015.11.009 
Podolsky, A., Kini, T., \& Darling-Hammond, L. (2019). Does teaching experience increase teacher effectiveness? A review of US research. Journal of Professional Capital and Community, 4(4), 286-308. doi:10.1108/JPCC-12-2018-0032

Polkowskia, Z., Jadejab, R., \& Duttac, N. (2020). Peer learning in technical educating and its worthiness: Some facts based on implementation. Procedia Computer Science 172, 247-252. doi:10.1016/j.procs.2020.05.039

Radha, V., \& Chandekar, P.A. (2013). Effect of engaged learning upon lecture learning method on outcome based education in Nursing - An experimental study. IOSR Journal of Research \& Method in Education, 3(2), 07-11. doi:10.9790/73880320711

Ribera T.B., Gato, M.P., Guillem, JMA, \& Pérez, C.M.D. (2014). Applying teamwork competence in a company course. In Peris-Ortiz, M., Garrigós-Simón, F. J., \& Pechuán, I. G. (eds). Innovation and Teaching Technologies. Switzerland: Springer International Publishing.

Safwat, A. M., \& Khorais, A. M. (2018). Effectiveness of a computer-based learning module on arterial blood gas interpretation among staff nurses in critical care units. Innovative Journal of Medical and Health Science, 8(3), 31-40. doi:10.15520/ijmhs.v8i3.2091

Stone, R., Cooper, S., \& Cant, R. (2013). The value of peer learning in undergraduate nursing education: A systematic review. ISRN Nursing, 2013(i), 1-10. doi:10.1155/2013/930901

Surabenjawong, U., Phrampus, P. E., Lutz, J., Farkas, D., Gopalakrishna, A., Monsomboon, A., ..., \& O'Donnell, J. M. (2020). Comparison of innovative peer-to-peer education and standard instruction on airway management skill training. Clinical Simulation in Nursing 47(C), 16-24. doi:10.1016/j.ecns.2020.06.009.

Tandel, M., Kanjiya, D., Vedi, N., Sharma, D., Sumati, \& Singh, P. (2019). Introduction of group discussion as a teaching - learning method in dissection hall for the first MBBS students. National Journal of Clinical Anatomy, 8(02), 066-070. doi:10.1055/s-0039-1692301

Wijnia, L, Loyens, S.M.M, \& Derous, E. (2011). Investigating effects of problem-based versus lecture-based learning environment on student motivation. Contemporary Educational Psychology, 36(2), 101-113. doi:10.1016/j.cedpsych.2010.11.003

$\mathrm{Xu}, \mathrm{J}-\mathrm{H}$. (2016). Toolbox of teaching strategies in nurse education. Chinese Nursing Research, 3, 54-57. doi:10.1016/j.cnre.2016.06.002

Yu, T.C., Wilson, N.C., Sigh, P.P., Lemanu, D.P., Hawken, S.J., \& Hill, AG (2011). Medical students as teachers: A systematic review of peer assisted teaching during medical school. Advances in Medical Education and Practice, 2, 157-172. doi:10.2147/AMEP.S14383 